\title{
An emerging tropical cyclone-deadly heat compound hazard
}

\author{
T. Matthews $\circledast^{1 \star}$, R. L. Wilby' and C. Murphy $\mathbb{(}^{2}$
}

\begin{abstract}
Climate change may bring new hazards through novel combinations of extreme weather (compound events)'. Here we evaluate the possibility of dangerous heat following major tropical cyclones (TCs)-a combination with serious potential consequences given that mega-blackouts may follow powerful $\mathrm{TCs}^{2}$, and the heavy reliance on air conditioning ${ }^{3}$. We show that 'TC-heat' events are already possible along densely populated coastlines globally but, to date, only an estimated 1,000 people have been impacted. However, this number could rise markedly with over two million at risk under a storyline of the observed TCs recurring in a world $2^{\circ} \mathrm{C}$ warmer than pre-industrial times. Using analogues as focusing events we show, for example, that if the catastrophic 1991 Bangladesh cyclone occurred with $2^{\circ} \mathrm{C}$ global warming, there would be $>70 \%$ chance of subsequent dangerous heat. This research highlights a gap in adaptation planning and a need to prepare for an emerging TC-heat compound hazard.
\end{abstract}

Extreme heat is a major threat to public health and a risk that is projected to rise with global warming ${ }^{4}$, even if temperatures are held below the Paris targets of 1.5 or $2^{\circ} \mathrm{C}\left(\right.$ ref. $\left.^{5}\right)$. With around 1.6 billion units in operation, air conditioning reduces vulnerability to extreme heat ${ }^{3,6}$. However, populations dependent on air conditioning may become highly exposed in the event of power failure ${ }^{7}$. Substantial electricity outages have already been caused by TCs, with the top three events (2013 Typhoon Haiyan, 2017 Hurricane Maria and 2012 Typhoon Bopha) incurring between 3.2 and 6.1 billion customer-hours of lost supply over one or two months ${ }^{2,8-10}$. Widespread heat-related mortality was not reported during these mega-blackouts but, given the rapid rise in dangerous humid heat projected at low latitudes ${ }^{4}$, we identify the growing threat of a catastrophic 'TC-heat' compound hazard. In this storyline, a TC first cripples electrical infrastructure and is then followed by deadly heat as the population tries to recover. Here, we provide the first assessment of the present and evolving risk of the TC-heat hazard under climate change.

We searched observational records (1979-2017) for compound TC-heat events, defined here as a major TC (central pressure $\leq 945 \mathrm{hPa}$ ) followed within $30 \mathrm{~d}$ by a heat index $(\mathrm{HI})>40.6^{\circ} \mathrm{C}$ at the site of landfall (see Methods). We use the HI because of its widespread operational use, not least by the United States National Weather Service, to communicate danger when values exceed $40.6^{\circ} \mathrm{C}$. We employ the same threshold to define onset of potentially deadly conditions. According to our criteria, TC-heat events have been vanishingly rare, with only four of the 121 major TCs that made landfall followed by maximum $\mathrm{HI} \geq 40.6^{\circ} \mathrm{C}$ (hereafter, $\mathrm{HI} 40.6$ ). All these events were in remote northwest Australia (Fig. 1a), where around 1,000 people were exposed. Given that nearly 40 million people live in the paths of the 121 major TCs, and that almost
6 million of them are routinely exposed to HI40.6 (99.9th percentile of HI40.6; Fig. 1b), it is fortunate that so few have been exposed to a compound TC-heat event.

We investigated reasons for the infrequent overlap of TCs and HI40.6 using the Northwest Pacific, South Indian and North Atlantic basins, which account for more than $85 \%$ of the TCs in our sample. Seasonal cycles of maximum TC probability and maximum HI40.6 occurrence are not generally in phase. In all three ocean basins, the maximum HI40.6 extent occurs before peak TC probability (Fig. 2). This is due to the difference in thermal inertia between land and ocean. Land heats up rapidly with the seasonal solar cycle, whereas sea surface temperatures take longer to peak and remain elevated whilst the land and atmosphere begin to cool, creating an environment with increased convective available potential energy suitable for intense $\mathrm{TCs}^{11,12}$. Figure 2 also reveals that the greatest overlap in seasonal curves of HI40.6 extent and major TC landfall probability is in the South Indian basin, suggesting that conditions there most favour TC-heat. This fits with our observation that northwest Australia (South Indian) is the only region to have experienced the hazard during the period of observations (Fig. 1a).

The rarity of TC-heat is due to asynchronous seasonal cycles of TC probability and HI40.6. Contrary to expectations ${ }^{13}$, TCs do not reduce the probability of HI40.6 after landfall by modifying the thermodynamic environment (Fig. 3). They arrive after anomalously high $\mathrm{HI}$ from amplified air temperatures and specific humidity, meaning the average $\mathrm{HI}$ anomaly in the $30 \mathrm{~d}$ before landfall $\left(0.45^{\circ} \mathrm{C}\right)$ is significantly different from zero according to a onesample, two-tailed Student's $t$-test $(\mathrm{t}=4.52, P<0.05)$. Passage of the TC then causes all variables, except specific humidity, to decrease, partially compensating for the fall in air temperature and thereby maintaining the HI. After TC passage, $\mathrm{HI}$ anomalies return to zero within approximately $10 \mathrm{~d}$ and the mean anomaly in the $30 \mathrm{~d}$ after landfall $\left(0.16^{\circ} \mathrm{C}\right)$ is not significantly different from zero $(t=1.34$, $P=0.18$ ). This return to the climatology results in a significant difference between $\mathrm{HI}$ anomalies before and after landfall according to a paired, two-sample $t$-test $(t=2.51, P<0.05)$. The passage of a TC therefore reduces the HI, but only from unusually high values to conditions consistent with long-term averages. This implies that the probability of HI 40.6 in the $30 \mathrm{~d}$ following TC landfall is not lower than in the same 30-day window in other years. The finding is robust when re-analysed with data from nearby weather stations (see Supplementary information).

A stochastic simulation was applied to gain deeper insight into the contemporary compound TC-heat hazard, and under climate change scenarios generated by pattern-scaling air temperature whilst holding relative humidity constant (for example, ref. ${ }^{14}$ ). Note that the independence between TCs and subsequent HI conditions means that the probability of HI40.6 for each TC reduces to the

'Department of Geography and Environment, Loughborough University, Loughborough, UK. ${ }^{2}$ rish Climate Analysis and Research Units, Department of Geography, Maynooth University, Maynooth, Ireland. *e-mail: t.matthews@lboro.ac.uk 


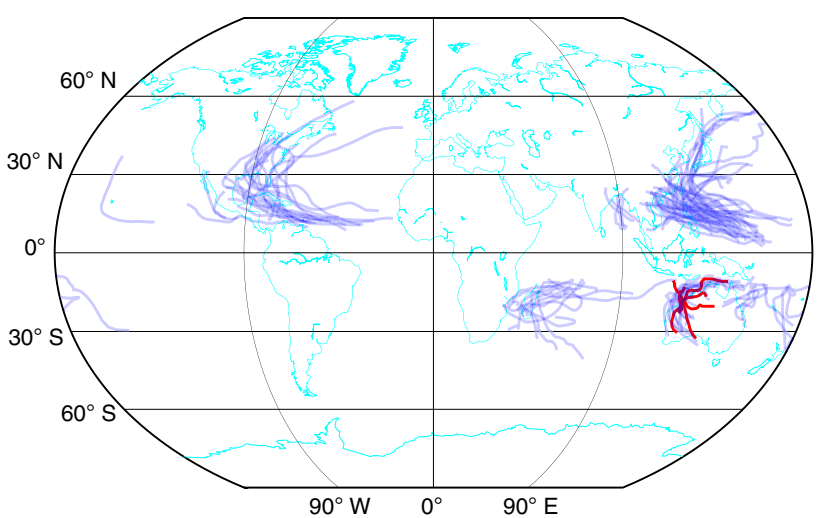

b

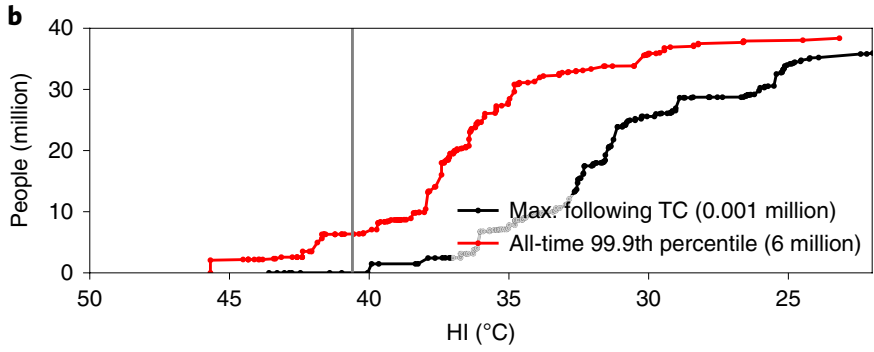

Fig. 1 | Observed TCs and extreme heat. a, Tracks of 121 major TCs. Red lines denote four TCs that were followed by HI 40.6 within $30 \mathrm{~d}$ of landfall. b, Number of people exposed to a maximum $\mathrm{HI}$ of at least the value given by the $x$ coordinate in the $30 \mathrm{~d}$ of TC landfall (black line). The red line denotes the number of people (living in the same TC-impacted grid cells) that experience a 99.9th percentile $\mathrm{HI}$ (all days of year) of at least the value given by the $x$ coordinate. Values in brackets in parentheses report series' intersection with HI40.6 (grey line).

climatological relative frequency of HI 40.6 within $30 \mathrm{~d}$ of the landfall date. These probabilities can be summed over TCs to compute the expected number of TC-heat events for each 30-year period, then used as weights to evaluate the expected number of people at risk (see Methods for details).

We find a rapid, non-linear increase in the number of TC-heat events as the climate warms (Fig. 4a). Under baseline conditions, the expected frequency is 0.10 compound events per year (three events per 30-year climate normal period), which matches the observed rate. If the global mean temperature rises by 1.5 or $2{ }^{\circ} \mathrm{C}$ above pre-industrial, the expected frequency per 30 years becomes 7 and 11 events, respectively. If global warming reaches $4^{\circ} \mathrm{C}$ (representing a high-emissions, end-of-century scenario), TC-heat events could occur at least annually (Fig. 4a).

The rising frequency of TC-heat hazards increases the number of people potentially affected (Fig. $4 \mathrm{~b}$ ). Under the 1.5 or $2{ }^{\circ} \mathrm{C}$ global warming scenario there could be, respectively, 1.2 or 2 million people at risk per 30 -year period, rising to 11.8 million for $4{ }^{\circ} \mathrm{C}$. Using the baseline temperature anomaly $\left(1981-2010,0.68^{\circ} \mathrm{C}\right.$ above pre-industrial; see Methods), our analysis yields an expectation of 0.4 million people affected during 1979-2017, indicating that TC-heat is already possible along densely populated coastlines and highlighting the good fortune that only approximately 1,000 people were affected over this period. We also anticipate an increase in the intensity of humid heat for people recovering from TCs. Figure $4 \mathrm{c}$ shows that extreme HI values averaged across TC landfall sites after landfall (see Methods) could rise almost 2.5-fold faster than global mean air temperature. As shown before, this is a consequence of the combined effect of rising air temperature and water vapour on humid heat ${ }^{15,16}$.

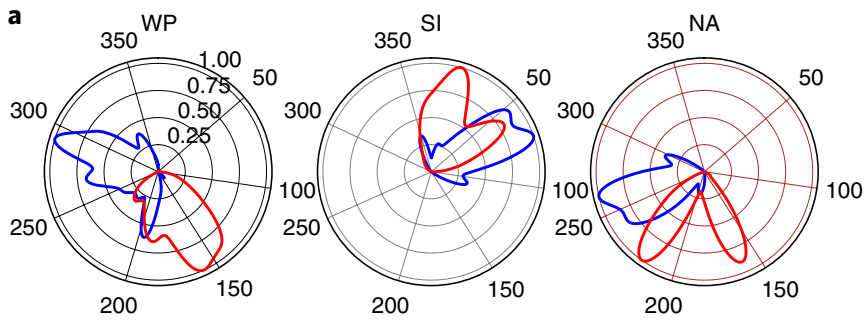

b

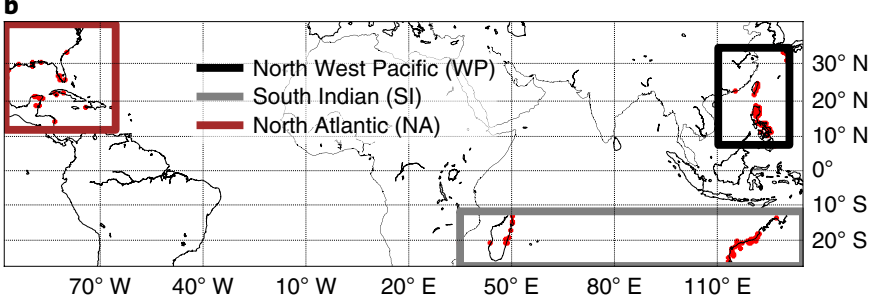

Fig. 2 | Seasonal climatologies for major TC occurrence and extent of HI 40.6 by ocean basin. a, Gaussian-smoothed day-of-year climatology for major TC landfall probability (blue) and HI40.6 occurrence (red). All series have been normalized by their respective maximum. Labels above the polar plots denote ocean basin; abbreviations shown in $\mathbf{b}$. Note that the angle of rotation indicates day of year (labelled). b, Map of the domains corresponding to the ocean basins. Red points mark locations impacted by major TCs: only these points in each domain were used to compute the HI40.6 climatology.

Observed TC tracks (analogues) help demonstrate the evolving TC-heat hazard. We identified TCs that could possibly (probability $>0$ ) or probably (probability $>0.5$ ) be followed by HI40.6 under the different scenarios of warming (Fig. 5 and Methods). Possible TCs under baseline conditions include very notable events, such as the 1991 Cyclone Marian that killed more than 138,000 people, affected over 15 million and left around one million homeless ${ }^{17}$. Whilst the actual $\mathrm{HI}$ peaked at $37.9^{\circ} \mathrm{C} 9 \mathrm{~d}$ after the TC made landfall in Bangladesh, the same 30-day window experienced HI40.6 in six separate years during the period 1981-2010. Neither the North Atlantic nor the Northwest Pacific basin has experienced a TC-heat event but our results suggest there have been near misses, with Hurricane Emily (maximum $\mathrm{HI}=38.3^{\circ} \mathrm{C}, 21 \mathrm{~d}$ after landfall) and Typhoon Rammasun (maximum $\mathrm{HI}=39.9^{\circ} \mathrm{C}, 6 \mathrm{~d}$ after landfall) amongst those identified as possible analogues. Emily struck the Caribbean and Mexico in July 2005, impacting thousands and causing billions of dollars' worth of damage, including to electricity infrastructure ${ }^{15}$. After Rammasun made landfall in the Philippines (July 2014), blackouts affected Manila and complaints about the hot weather were reported in the media ${ }^{16}$. As expected from Fig. 2, early-season landfall is a common feature of these analogues. All but one of the 13 possible TCs in the three basins mentioned above occurred before the peak likelihood of a major TC landfall in each basin.

When the HI is scaled for global warming, many possible analogues transition to probable. Typhoon Rammasun and Hurricane Emily achieve this status with $1.5^{\circ} \mathrm{C}$ warming (probable at 1.25 and $1.5^{\circ} \mathrm{C}$, respectively), whereas Cyclone Marian transitions under the $2^{\circ} \mathrm{C}$ scenario (at $1.75^{\circ} \mathrm{C}$ ). Under a $4^{\circ} \mathrm{C}$ scenario, the number of probable analogues increases substantially. These include 2017 Hurricane Harvey (at $2.25^{\circ} \mathrm{C}$ of warming) and 2005 Hurricane Katrina (at $3.5^{\circ} \mathrm{C}$ ). At $4{ }^{\circ} \mathrm{C}$, Typhoon Haiyan-the cause of the largest blackout in history-becomes a probable analogue with $>70 \%$ likelihood of being followed by HI40.6.

Our assessment shows that TC-heat events are rare but already possible along some of the most densely populated coastlines 

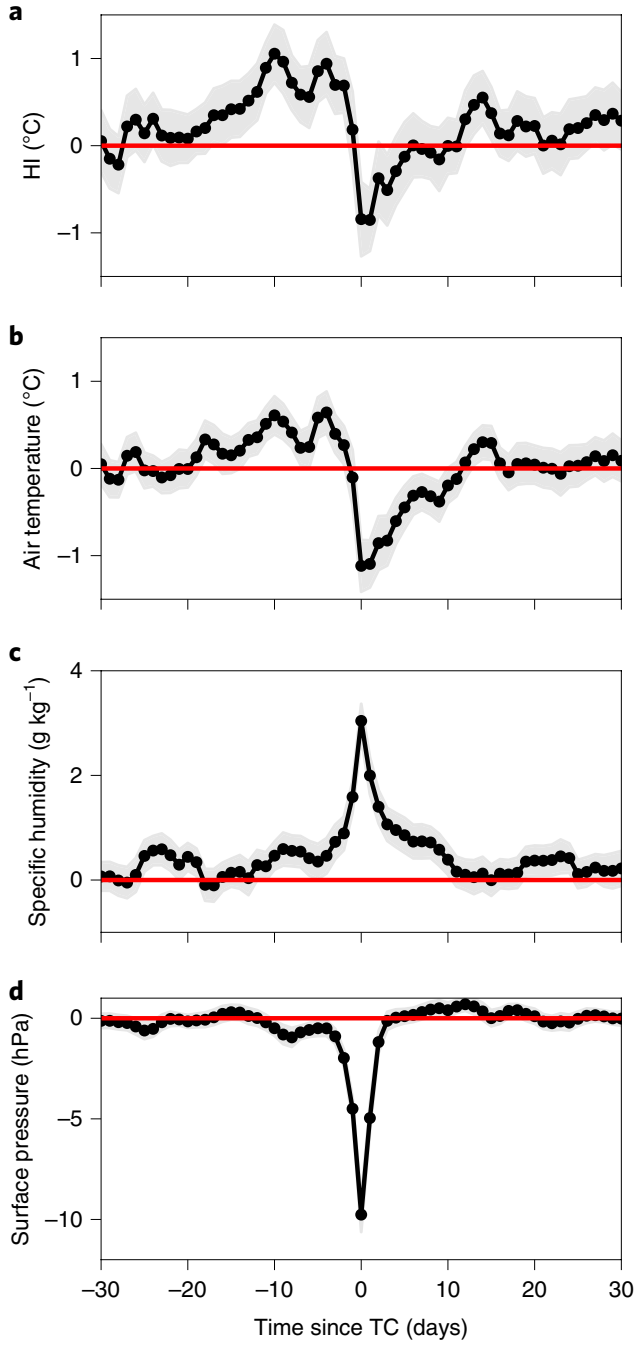

Fig. 3 | Composite impact of a major TC passage on meteorology across all ocean basins. a-d, $\mathrm{HI}$ (a), 2-m air temperature (b), specific humidity (c) and surface air pressure (d). The red line denotes zero and the grey shading spans an anomaly of \pm 2 s.e.m. Anomalies were calculated from a day-ofyear climatology using the same Gaussian kernel procedure as in Fig. 2.

on Earth. With no change in TCs, the likelihood of TC-heat is expected to increase rapidly with warming, consistent with more frequent and dangerous heatwaves in lower latitudes under climate change ${ }^{4,14}$. The growing dependence on air conditioning in countries at risk of $\mathrm{TCs}^{6}$ is therefore of concern, particularly so given that it may decrease humans' natural thermal adaptability?

The threat of TC-heat may not be restricted to those affected by loss of air conditioning. Some of the TCs already mentioned displaced millions of people, and relief housing may not provide safe refuge from extreme heat ${ }^{18}$. Furthermore, humanitarian operations in the wake of TCs can involve large numbers of non-native personnel, such as the 7,600+ US troops arriving after Cyclone Marian ${ }^{19}$. People require several days to acclimatize and improve their physiological response to extreme heat ${ }^{20}$, placing such rescue workers at higher risk. Evacuations ahead of major TCs may also become progressively more dangerous with climate warming, because our results show that the HI is anomalously high before major TCs make landfall.

Our assessment of evolving TC-heat is subject to some important caveats. First, we use the storyline of 'no change' in TCs, yet major TCs are likely to become more frequent with warming ${ }^{21}$.
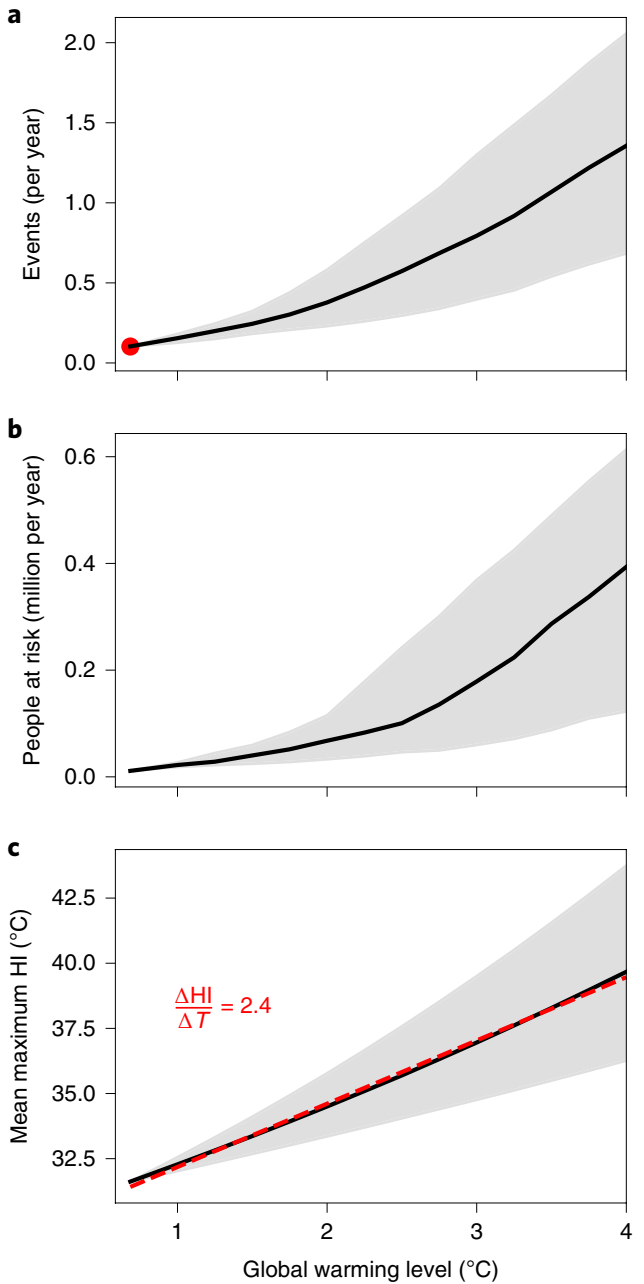

Fig. 4 | Change in TC-heat hazard under climate change. a, Expected number of compound TC-heat events as a function of global warming level. Shading spans the uncertainty range from repeating the analysis using the 5th and 95th percentiles of pattern-scaling coefficients; black line denotes the ensemble mean coefficients; red dot is the observed TC-heat event rate. $\mathbf{b}$, As in $\mathbf{a}$ but for the expected number of people directly impacted by TC-heat events. $\mathbf{c}, \mathrm{As} \mathbf{a}, \mathbf{b}$, but for mean maximum $\mathrm{HI}$ after TC landfall (see Methods). The red dotted line (slope annotated) is the best-fit linear approximation of the black curve.

Changes in seasonality are more uncertain ${ }^{22}$, but the likelihood of TC-heat would be expected to increase more rapidly if future TCs occur earlier in the year (cf. Fig. 2). Second, our pattern-scaling assumes uniform changes across the temperature distribution and constant relative humidity. The even temperature increase is probably conservative because greater warming is expected at higher quantiles ${ }^{23}$. Climate model projections suggest modest reductions in mean relative humidity over land and even more subtle increases over ocean ${ }^{24}$, supporting our constant relative humidity treatment given the transitionary nature (ocean/land) of the coastal locations impacted by TCs. Even so, such statements refer to mean quantities, and little is known about relative humidity changes during extreme heat events in the low latitudes. Third, we assume a 2015 population, so our assessment reflects only the increasing hazard frequency and not the changing population exposure or their vulnerability. Low-latitude regions are projected to have rapid population growth over the twenty-first century, adding many more people to the regions with the highest increases in deadly humid heat ${ }^{25}$. 
a
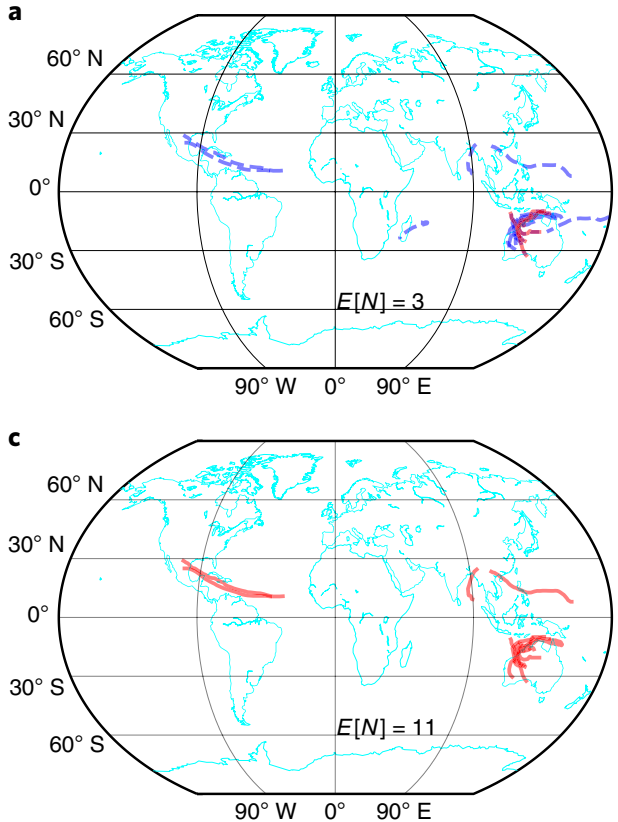

b

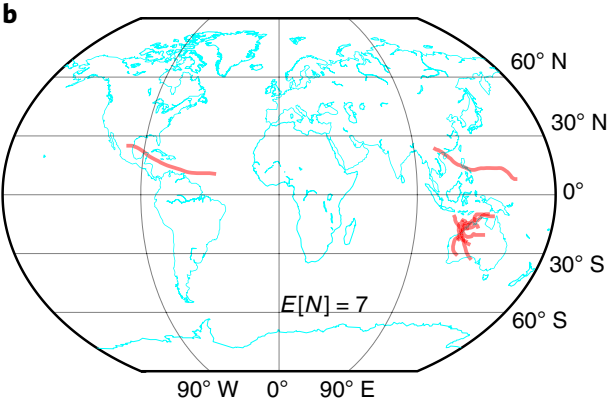

d

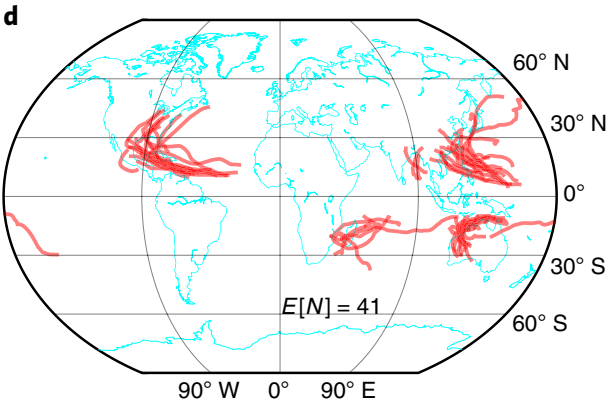

Fig. 5 | Analogue major TCs under climate warming. a-d, Major probable TC tracks (with at least a $50 \%$ chance of experiencing HI40.6 in the $30 \mathrm{~d}$ following landfall) are plotted for various levels of global warming: baseline (a), $1.5^{\circ} \mathrm{C}(\mathbf{b}), 2.0^{\circ} \mathrm{C}(\mathbf{c})$ and $4.0^{\circ} \mathrm{C}(\mathbf{d})$. For the baseline (a, $\left.1981-2010\right)$, we also indicate (by dotted blue lines) potential TC tracks (with non-zero probability of being followed by HI40.6). Each panel shows the expected number of compound TC-heat hazards in a 30-year period ( $E[N]$ ), rounded to the nearest integer).

Overall, our assessment therefore provides a lower-bound estimate of the increasing number of people likely to be exposed to TC-heat as the climate warms. Understanding could be improved by assessing TC climatologies projected by next-generation ensembles of high-resolution, coupled physical models ${ }^{26}$ or through downscaling $^{27}$. TCs and humid heat are physically connected through moist enthalpy in the lower atmosphere ${ }^{25,28}$, so future work focusing on this diagnostic under climate change could improve understanding of evolving risks in low latitudes. Future studies could also add more depth to the understanding of TC-heat impacts by explicitly modelling excess mortality as a function of humid heat, including the impact of increased vulnerability stemming from assumed airconditioning loss ${ }^{29}$.

Finally, our results present a simple but stark warning: with no change in TCs but plausible rises in the HI, potentially deadly heatwaves are more likely to follow TCs and eventually strike vulnerable populations. Although a TC-heat event has not yet impacted a heavily populated coastline, the likelihood is growing. The absence of experience in dealing with such a compound hazard places those exposed communities at even greater risk ${ }^{1}$. By drawing attention to this emergent hazard, we trust that our study will stimulate further research and adaptation planning to protect those at growing risk from a TC-heat compound event.

\section{Online content}

Any methods, additional references, Nature Research reporting summaries, source data, statements of code and data availability and associated accession codes are available at https://doi.org/10.1038/ s41558-019-0525-6.

Received: 4 September 2018; Accepted: 6 June 2019; Published online: 22 July 2019

\section{References}

1. Zscheischler, J. et al. Future climate risk from compound events. Nat. Clim. Change 8, 469-477 (2018).
2. Houser, T. \& Marsters, P. The World's Second Largest Blackout (Rhodium Group, 2018); https://rhg.com/research/puerto-rico-hurricane-maria-worldssecond-largest-blackout/

3. Barreca, A., Clay, K., Deschenes, O., Greenstone, M. \& Shapiro, J. S. Adapting to climate change: the remarkable decline in the U.S. temperature-mortality relationship over the twentieth century. J. Political Econ. 124, 105-159 (2016).

4. Mora, C. et al. Global risk of deadly heat. Nat. Clim. Change 7, 501-506 (2017).

5. Vicedo-Cabrera, A. M. et al. Temperature-related mortality impacts under and beyond Paris agreement climate change scenarios. Clim. Change 150, 391-402 (2018)

6. The Future of Cooling: Opportunities for Energy-efficient Air Conditioning (International Energy Agency, 2018).

7. Yu, J. et al. A comparison of the thermal adaptability of people accustomed to air-conditioned environments and naturally ventilated environments. Indoor Air 22, 110-118 (2012).

8. Abi-Samra, N., McConnach, J., Mukhopadhyay, S. \& Wojszczyk, B. When the bough breaks: managing extreme weather events affecting electrical power grids. IEEE Power Energy Mag. 12, 61-65 (2014).

9. Hurricanes Maria and Irma November 20 Event Summary Report No. 78; 1-5 (US Department of Energy, Infrastructure Security \& Energy Restoration, 2017)

10. Typhoon Bopha Situation Report No. 16 (UN Office for the Coordination of Humanitarian Affairs, 2013).

11. Emanuel, K. A. The maximum intensity of hurricanes. J. Atmos. Sci. 45, 1143-1155 (1988).

12. Hart, R. E., Maue, R. N. \& Watson, M. C. Estimating local memory of tropical cyclones through MPI anomaly evolution. Mon. Weather Rev. 135, 3990-4005 (2007)

13. Sriver, R. L. \& Huber, M. Observational evidence for an ocean heat pump induced by tropical cyclones. Nature 447, 577-580 (2007).

14. Matthews, T. K. R., Wilby, R. L. \& Murphy, C. Communicating the deadly consequences of global warming for human heat stress. Proc. Natl Acad. Sci. USA 114, 3861-3866 (2017).

15. Beven, J. L. et al. Atlantic hurricane season of 2005. Mon. Weather Rev. 136, 1109-1173 (2008).

16. Morella, C. Power outages continue in Philippines following typhoon. UCA News (17 July 2014).

17. Guha-Sapir, D., Below, R. \& Hoyois, P. The CRED/OFDA International Disaster Database (EM-DAT, accessed 9 August 2018); www.emdat.be

18. Albadra, D., Coley, D. \& Hart, J. Toward healthy housing for the displaced. J. Archit. 23, 115-136 (2018).

19. McCarthy, P. Operation Sea Angel: A Case Study (US Army, 1994). 
20. Hanna, E. G. \& Tait, P. W. Limitations to thermoregulation and acclimatization challenge human adaptation to global warming. Int. J. Environ. Res. Public Health 12, 8034-8074 (2015).

21. Camargo, S. J. Global and regional aspects of tropical cyclone activity in the CMIP5 models. J. Climatol. 26, 9880-9902 (2013).

22. Dwyer, J. G. et al. Projected twenty-first-century changes in the length of the tropical cyclone season. J. Climatol. 28, 6181-6192 (2015).

23. Lewis, S. C. \& King, A. D. Evolution of mean, variance and extremes in 21 st century temperatures. Weather Clim. Extrem. 15, 1-10 (2017).

24. Byrne, M. P. \& O'Gorman, P. A. Link between land-ocean warming contrast and surface relative humidities in simulations with coupled climate models. Geophys. Res. Lett. 40, 5223-5227 (2013).

25. Matthews, T. Humid heat and climate change. Prog. Phys. Geogr. 42, 391-405 (2018).

26. Haarsma, R. J. et al. High resolution model intercomparison project (HighResMIPv1.0) for CMIP6. Geosci. Model. 9, 4185-4208 (2016).

27. Lin, N. \& Emanuel, K. Grey swan tropical cyclones. Nat. Clim. Change 6, 106-111 (2016).

28. Kang, N.-Y. \& Elsner, J. B. Trade-off between intensity and frequency of global tropical cyclones. Nat. Clim. Change 5, 661-664 (2015).

29. Petkova Elisaveta, P. et al. Towards more comprehensive projections of urban heat-related mortality: estimates for New York City under multiple population, adaptation, and climate scenarios. Environ. Health Perspect. 125 47-55 (2017).

\section{Acknowledgements}

The authors thank M. Foote for discussion on the TC-heat hazard before TCs make landfall.

\section{Author contributions}

T.M. conceived the study and conducted the analysis. All authors contributed equally to study design and writing the manuscript.

\section{Competing interests}

The authors declare no competing interests.

\section{Additional information}

Supplementary information is available for this paper at https://doi.org/10.1038/ s41558-019-0525-6.

Reprints and permissions information is available at www.nature.com/reprints. Correspondence and requests for materials should be addressed to T.M.

Peer review information: Nature Climate Change thanks Ning Lin, Jakob Zscheischler and the other anonymous reviewer(s) for their contribution to the peer review of this work.

Publisher's note: Springer Nature remains neutral with regard to jurisdictional claims in published maps and institutional affiliations.

(C) The Author(s), under exclusive licence to Springer Nature Limited 2019 


\section{Methods}

Heat index. Following previous climate change studies ${ }^{14,30-32}$, we used the HI to characterize humid heat under climate change. We calculated the $\mathrm{HI}$ as in ref. ${ }^{3: 3}$ using 2-m air temperature, 2-m specific humidity and surface pressure from the WATCH-Forcing-Data-ERA-Interim (WFDEI) dataset ${ }^{34}$, which constitutes ECMWF Re-Analysis (ERA)-Interim reanalysis data ${ }^{35}$ interpolated and corrected to land observations on a $0.5^{\circ} \times 0.5^{\circ}$ grid. Specific humidity was converted to relative humidity using surface air pressure and the table look-up procedure (RELHUM) available in the NCL programming language (v.6.5.0). Because WFDEI data are available for the period 1979-2015, we extended the record to the end of 2017 by bias-correcting the ERA-Interim reanalysis ${ }^{35}$, using the quantile mapping procedure described in ref. ${ }^{36}$, but with separate correction functions derived for each calendar month. All corrections were applied at intervals of one percentile.

Tropical cyclones and observations. The coordinates, distances to land, ocean basins and central air pressures of TCs were extracted from IBTrACS v.4 (beta), using data from 1979-2017 to overlap with the (extended) WFDEI record. Central air pressure was used to identify 'major' landfalling TCs, defined as those whose centre was at some point over land whilst the pressure was no higher than $945 \mathrm{hPa}$ (corresponding to at least a Category 3 hurricane according to the Saffir-Simpson damage potential index ${ }^{37}$ ). We chose a definition of intensity based on central pressure, because this variable is reported more consistently by different agencies than maximum sustained wind speed ${ }^{38}$. This filtering procedure left us with $121 \mathrm{TCs}$.

The evolution of the surface meteorology at the sites of TC landfall was assessed by extracting time series from the nearest-neighbour land grid points in the WFDEI dataset for all time steps when the respective TC was over land and still of 'major' status (that is, $\leq 945 \mathrm{hPa}$ ). This process yielded 181 locations (grid points) across the 121 TCs. The number of land grid points impacted by each TC varied between one and six, although most ( 91\%) TCs impacted no more than two land grid points. The frequency of TC-heat events was then determined by the number of TCs that had HI 40.6 in at least one grid cell during the $30 \mathrm{~d}$ after landfall. Note that $30 \mathrm{~d}$ is a conservative search window given that longer mega-blackouts have followed some TCs (see main text).

The number of people exposed to different HI values was assessed using the $0.042 \times 0.042^{\circ}(2.5 \mathrm{~min})$ gridded 2015 population dataset available from ref. ${ }^{39}$. For each of the 181 locations impacted by major TCs, person-counts were extracted from all $0.042^{\circ}$ grid cells falling within the respective $0.5 \times 0.5^{\circ}$ WFDEI grid cell. In Fig. $1 \mathrm{~b}$ we show the number of people as a function of (1) the maximum HI endured in the $30 \mathrm{~d}$ following TC landfall and (2) the all-time 99.9th percentile in the $\mathrm{HI}$ (a value occurring on average $3 \mathrm{~d}$ per decade). This general function can be written as

$$
\operatorname{Pop}(\mathrm{HI})=\sum \operatorname{Pop}_{i, j} \times f\left(\hat{\mathrm{HI}}_{i, j}-\mathrm{HI}\right)
$$

where Pop denotes the total population exposed to a heat hazard (HI: either the maximum in the $30 \mathrm{~d}$ following TC landfall or the all-time 99.9th percentile) of at least $\mathrm{HI}{ }^{\circ} \mathrm{C} ; i$ and $j$ are the 181 row/column indices of the population (and WFDEI) grid, and the function $f$ evaluates to 1 when $\hat{\mathrm{HI}}_{i, j}$ is $\geq \mathrm{HI}$ and it is otherwise zero.

To explore the rarity of compound TC-heat hazards, we computed day-ofyear probabilities of major TC landfall for the Northwest Pacific, South Indian and North Atlantic basins. These three oceans accounted for more than $85 \%$ of all major TC landfall events during the period 1979-2017. Probabilities were derived for each basin by counting for each day of the year (1-366) the number of times a TC made landfall somewhere in the basin, then dividing the total by the number of years of TC data $\left(n_{\mathrm{TC}}=2017-1979+1=39\right.$ years). We used the same approach to compute the mean day-of-year fraction of grid points experiencing HI40.6 in each basin. Note that only HI data from grid cells impacted by major TCs were considered in this averaging (see Fig. 2). These day-of-year series (probability of TC landfall, and fraction of grid points with HI40.6) were smoothed with a Gaussian kernel with standard deviation $(\sigma)$ of $15 / 1.96=7.7$ days, meaning that $95 \%$ of the kernel weight was applied to a one-month period centred on the day of interest. Smoothed series were then normalized by their respective maxima (Fig. 3).

The extent to which TC passage impacts the meteorological environment (Fig. 3) was assessed by screening anomalies at the 181 grid cells found to have experienced a major TC landfall during 1979-2017. We calculated anomalies by subtracting the seasonal cycle, generated by computing a day-of-year mean for each meteorological variable (1979-2017), before smoothing with the same Gaussian kernel $(\sigma=7.7 \mathrm{~d})$.

The impact of each of the $121 \mathrm{TCs}$ on HI before and after landfall was evaluated statistically by averaging $\mathrm{HI}$ anomalies for the $30 \mathrm{~d}$ either side of their landfall date. We then subjected these before/after series, each comprising 121 values, to a onesample $t$-test to investigate the null hypothesis that TCs do not result in HI being different from the climatology (that is, the population means for the anomalies were zero). The test statistic $t$ is given by

$$
t=\frac{\overline{\mathrm{HI}}}{\sigma^{\prime}}
$$

where $\overline{\mathrm{HI}}$ denotes the sample mean and $\sigma^{\prime}$ is the sample standard deviation.
To investigate the change in HI following TC passage, we also applied a dependent $t$-test for paired samples, for which $t$ was computed:

$$
t=\frac{\overline{\Delta \mathrm{HI}}}{\Delta \sigma^{\prime}}
$$

where $\overline{\Delta \mathrm{HI}}$ denotes the mean of the 121 paired differences between the before/ after series, and $\Delta \sigma^{\prime}$ is the standard deviation of these differences. In this instance, the null hypothesis was for no change in HI following TC passage (that is, the population mean of the paired differences in mean $\mathrm{HI}$ anomalies was zero). We used Student's $t$-distribution with 120 degrees of freedom to test these null hypotheses, concluding that TC impacts on the HI were statistically significant when $P \leq 0.05$.

Scaling HI to simulate climate warming. We used pattern-scaling to explore the effect of climate warming on the probability of a compound TC-heat hazard. Temperatures $(T)$ from the baseline climate (1981-2010) were re-scaled following

$$
T_{i, j, d, w}=T_{i, j, d}+\beta_{i, j, d}(w-c)
$$

where $i$ and $j$ retain their meaning as WFDEI row/column indices, and $d$ represents the day of the year. The regression slope $\beta$ quantifies the local change in running 30 -year mean air temperature per degree of running 30-year average of the global mean air temperature. The value of $\beta$ was obtained at daily resolution by performing separate regressions for each month of the year, followed by linear interpolation of the slope coefficient to daily resolution. The regression analysis was performed with a sample of 58 CMIP5 model runs (see Supplementary information for an inventory). We mainly used the ensemble mean in the analysis, but the 5th and 95th percentiles of $\beta$ across the ensemble were also used to derive the uncertainty range in Fig. 4. The level of climate warming $(w)$ was incremented between 1 and $4^{\circ} \mathrm{C}$ in steps of $0.25^{\circ} \mathrm{C}$. The constant subtracted from $w\left(c=0.68^{\circ} \mathrm{C}\right)$ represents the amount by which 1981-2010 was warmer than pre-industrial (defined here as the average warming since 1880-1909 across datasets HadCRUT4 (ref. ${ }^{40}$ ), GISS ${ }^{41}$ and $\mathrm{BEST}^{42}$ ). Scaled $T$ values from equation (4) were used in the $\mathrm{HI}$ algorithm along with the original relative humidity to compute daily $\mathrm{HI}$ values under the warmer climates. Transforming the observed HI distribution in this way is consistent with previous studies ${ }^{14,43}$, and has been shown to yield results at the global scale similar to daily resolution projections of $\mathrm{HI}$ from climate models ${ }^{14}$. We prefer this scaling of observed HI over direct use of climate model integrations because of the considerable cold bias in modelled heat-humidity indices in the low-latitude domain of $\mathrm{TCs}^{32}$.

\section{Expected frequency of compound hazard and estimates of the population} at risk. Observed independence between TC occurrence and subsequent $\mathrm{HI}$ conditions was represented within a stochastic simulation to gain deeper insight into the compound TC-deadly heat hazard for the present climate (baseline, 1981-2010) and under scenarios of global warming. We adopt this stochastic, observation-driven approach because observed TC tracks are not reproduced well by climate model simulations in the most complete global ensemble available $\left(\right.$ CMIP5) ${ }^{21}$. Moreover, even very high-resolution model simulations presently struggle to capture the important intricacies of the TC climatology required for assessment of the TC-heat hazard (such as TC seasonality in all basins or extent of sea surface cooling $)^{44}$.

We computed the expected number of TC-heat events given the $121 \mathrm{TCs}$ and the HI climatology using

$$
E[N]=\sum_{k=1}^{k=121} E\left[N_{k}\right]
$$

where $E\left[N_{k}\right]$ is the expectation for each TC, defined (for example, ref. ${ }^{45}$ ) as

$$
E\left[N_{k}\right]=\sum_{x} x P\left\{N_{k}=x\right\}
$$

in which $P$ denotes probability and $x$ is assigned the value of either 1 (HI 40.6 follows TC within $30 \mathrm{~d}$ ) or 0 (it does not). Setting $P_{k}=P\left\{N_{k}=1\right\}$, it is clear that $E\left[N_{k}\right]$ is simply the probability of HI 40.6 :

$$
E\left[N_{k}\right]=P_{k}
$$

We computed this probability using the observed climatology, extracting 1981-2010 WFDEI HI data from the sites of TC landfall for the $30 \mathrm{~d}$ following landfall date, irrespective of the year in which the TC occurred. This provides a 900-d ensemble of HI data ( 30 years of $30 \mathrm{~d}$ ) for each of the $121 \mathrm{TCs}$. We then calculated how many times HI40.6 occurred at least once in each of the 30 years, yielding the probability of HI40.6:

$$
P_{k}=\frac{1}{30} \sum_{y=1981}^{y=2010} \min \left\{1, \sum_{l=1}^{l=\text { nloc }} f\left(\mathrm{TC}_{k, l}, \mathrm{HI}_{k, l, y}\right)\right\}
$$


where nloc is the number of grid points impacted by the respective TC (indexed by $k$ ) and the function, $f$, evaluates to 1 if the maximum $\mathrm{HI}$ in the 30 -d post-landfall sample in year $y$ at landfall location $l$ exceeds HI40.6, otherwise 0 . Note that nloc ranges between 1 and 6 across all TCs.

To compute the expected number of people impacted by TC-heat $(E[P])$ we

$$
E[P]=\sum_{k=1}^{k=121} E\left[P_{k}\right]
$$

where $P_{k}$ is the expected number of people for each TC, which is defined as

$$
E\left[P_{k}\right]=\sum_{l=1}^{l=\text { nloc }} \operatorname{pop}_{k, l} P_{k, l}
$$

in which pop p $_{k, l}$ is the population estimate for grid point $l$ impacted by TC $k$. Note that $P_{k, l}$ has the same meaning as in equation (7), although this time the $l$ index highlights that probabilities are computed for each location impacted by the TC:

$$
P_{k, l}=\frac{1}{30} \sum_{y=1981}^{y=2010} f\left(T C_{k, l}, \mathrm{HI}_{k, l, y}\right)
$$

$E[N]$ and $E[P]$ as calculated from equations (5) and (9) yield the expected number of TC-heat events and people impacted given the 121 major TC tracks and the climate of 1981-2010; conversion to expected annual statistics was achieved by dividing by the number of years of TC data $(1979-2017=39$ years $)$.

Whilst the HI40.6 metric enables us to track the changing frequency of compound TC-heat hazards, we recognize that populations may be differentially impacted by such events due to local variations in levels of acclimatization. Therefore, we also computed the changing intensity of humid heat, defined as the mean maximum $\mathrm{HI}$ in the $30 \mathrm{~d}$ following landfall, averaged across all 30 years and 121 TCs:

$$
\overline{\mathrm{HI}}_{\max }=\frac{1}{30 \times 121} \sum_{k=1}^{k=121} \sum_{y=1981}^{y=2010} \max \left(\mathrm{HI}_{k, y}\right)
$$

We evaluated equations (5)-(12) using the baseline climate, before repeating them using the pattern-scaled climates to assess the changing TC-heat compound hazard as a function of global warming.

Analogues. We used analogues to explore regions at risk and the potential impact of the TC-deadly heat hazard. Analogues draw on known cases (the actual occurrence of the TC, complete with experienced impacts) to infer new consequences (the potential impacts of a TC followed by deadly heat). This approach can help non-specialists comprehend the unknown $n^{14,46,47}$. Here, we assigned the terms possible and probable to those TCs with $P_{k}>0$ and $P_{k}>0.5$, respectively. These analogues then illustrate potential impacts to raise awareness of the emerging TC-heat compound hazard.

\section{Data availability}

The data that support the findings of this study are available from the corresponding author upon request.

\section{References}

30. Delworth, T. L., Mahlman, J. D. \& Knutson, T. R. Changes in heat index associated with $\mathrm{CO}_{2}$-Induced global warming. Clim. Change 43, 369-386 (1999)

31. Diffenbaugh, N. S., Pal, J. S., Giorgi, F. \& Gao, X. Heat stress intensification in the Mediterranean climate change hotspot. Geophys. Res. Lett. 34, L11706 (2007).

32. Zhao, Y., Ducharne, A., Sultan, B., Braconnot, P. \& Vautard, R. Estimating heat stress from climate-based indicators: present-day biases and future spreads in the CMIP5 global climate model ensemble. Environ. Res. Lett. 10, 084013 (2015)

33. Anderson, G. B., Bell, M. L. \& Peng, R. D. Methods to calculate the heat index as an exposure metric in environmental health research. Environ. Health Perspect. 121, 1111-1119 (2013).

34. Weedon Graham, P. et al. The WFDEI meteorological forcing data set: WATCH forcing data methodology applied to ERA-Interim reanalysis data. Water Resour. Res. 50, 7505-7514 (2014).

35. Dee, D. P. et al. The ERA-Interim reanalysis: configuration and performance of the data assimilation system. QJR Meteorol. Soc. 137, 553-597 (2011).

36. Rye, C. J., Arnold, N. S., Willis, I. C. \& Kohler, J. Modeling the surface mass balance of a high Arctic glacier using the ERA-40 reanalysis. J. Geophys. Res. Earth Surf. 115, F02014 (2010).

37. Kantha, L. Time to replace the Saffir-Simpson hurricane scale? EOS Trans. Am. Geophys. Union 87, 3-6 (2006).

38. International Best Track Archive for Climate Stewardship (IBTrACS) Technical Documentation (BTrACS Science Team, 2018).

39. Gridded Population of the World, Version 4 (GPWv4): Population Count Adjusted to Match 2015 Revision of UN WPP Country Totals, Revision 10 (Center for International Earth Science Information Network, Columbia University, 2017); http://sedac.ciesin.columbia.edu/data/set/gpw-v4population-count-adjusted-to-2015-unwpp-country-totals-rev10/metadata

40. Morice, C. P., Kennedy, J. J., Rayner, N. A. \& Jones, P. D. Quantifying uncertainties in global and regional temperature change using an ensemble of observational estimates: the HadCRUT4 data set. J. Geophys. Res. Atmos. 117, D08101 (2012).

41. Hansen, J., Ruedy, R., Sato, M. \& Lo, K. Global surface temperature change. Rev. Geophys. 48, (2010).

42. Muller, R. A. et al. A new estimate of the average earth surface land temperature spanning 1753 to 2011. Geoinform. Geostat. https://doi. org/10.4172/2327-4581.1000101 (2013).

43. Willett, K. M. \& Sherwood, S. Exceedance of heat index thresholds for 15 regions under a warming climate using the wet-bulb globe temperature. Int. J. Climatol. 32, 161-177 (2012).

44. Murakami, H. et al. Simulation and prediction of category 4 and 5 hurricanes in the high-resolution GFDL HiFLOR coupled climate model. J. Clim. 28 9058-9079 (2015)

45. Wilks, D. S. Statistical Methods in the Atmospheric Sciences (Academic Press, 2011).

46. Glantz, M. H. The use of analogies: in forecasting ecological and societal responses to global warming. Environ. Sci. Policy Sustain. Dev. 33, 10-33 (1991).

47. Matthews, T., Mullan, D., Wilby, R. L., Broderick, C. \& Murphy, C. Past and future climate change in the context of memorable seasonal extremes. Clim. Risk Manag. 11, 37-52 (2016). 